\title{
THE EXPRESSIVE PATTERN OF LAUGHTER
}

\author{
WILLIBALD RUCH* and PAUL EKMAN ${ }^{\circ}$ \\ *Department of Physiological Psychology, Heinrich-Heine-Universität Düsseldorf, \\ Universitätsstraße 1, 40225 Düsseldorf, Germany \\ ${ }^{\circ}$ Human Interaction Laboratory, University of California as San Francisco, 401 \\ Parnassus Avenue, San Francisco 94143, USA
}

\begin{abstract}
Laughter as a vocal expressive-communicative signal is one of the least understood and most frequently overlooked human behaviors. The chapter provides an overview of what we know about laughter in terms of respiration, vocalization, facial action, and body movement and attempts to illustrate the mechanisms of laughter and to define its elements. The importance of discriminating between spontaneous and contrived laughter is pointed out and it is argued that unrestrained spontaneous laughter involves inarticulate vocalization. It is argued that we need research integrating the different systems in laughter including experience.
\end{abstract}

Laughter is a conspicuous but frequently overlooked human phenomenon. In ontogenetic development it emerges, later than smiling, around the fourth month; however, cases of gelastic epilepsy (from Greek; gelos = laughter) among neonates demonstrate that all structures are there and functional on date of birth. Further evidence for its innateness comes from twin studies as well as from the fact that laughter is easily observable among deaf-blind children (even among deaf-blind thalidomide children, who could not "learn" laughter by touching people's faces).

Man is not the only animal that laughs. Like smiling, laughter has its equivalent in the repertoire of some nonhuman primates. Beginning with Darwin (1872), many writers have been struck by the notable acoustic, orofacial, and contextual similarities between chimpanzee and human laughter. Especially among juvenile chimpanzees a "play-face" with associated vocalization was noted to accompany actions such as play, tickling, or play-biting (Preuschoft, 1995; van Hooff, 1972).

\section{Laughter as an Inarticulate Utterance}

Laughter is estimated to be about 7 million years old (Niemitz, 1990). There is disagreement on how human speech developed phylogenetically. It could have originated from non-verbal vocal utterances, a prelingual gestural system, or sounds initially used to supplement the facial channel. However, it is safe to assume that laughter-like other utterances such as moan, sigh, cry, groan, etc.- was there before man developed speech and served as an expressive-communicative social signal.

Considering the stage in the evolution of voice when laughter emerged allows us to make several deductions about the nature of the sound, its generation and the 
cerebral organization of laughter. If laughter was part of the human vocal repertoire before the speech centers were developed, it is likely that the sound was generated almost exclusively by laryngeal modulations, modified to some degree by supralaryngeal activity but not by articulation. This is because articulation requires voluntary control over the vocal system. Thus the production of speech sounds needs the coordination of respiration, phonation, resonance, and articulation, an analysis of laughter will involve mainly the consideration of the first three. But is it consistent with current knowledge to hypothesize that a laugh-pulse -a vocalization segment initiated by an aspirated "h" type sound followed by the utterance of one of several vowel sounds that is then abruptly terminated- is an inarticulate sound? Indeed, the $/ \mathrm{h} /$, an voiceless fricative glottal sound, is the only consonant produced at the level of the larynx; but as laughter is not "speech" we should not expect phonemes of a language to be uttered. Likewise, the assumption of resting articulators would suggest that the laughter "vowel" (but also the sound for other prelingual utterances, such as moaning or utterances of astonishment) is the central vowel schwa, or /e/ (as in about). For the production of this "neutral vowel" one needs to open the mouth and lower the jaw, but keep all other articulators passive. We know from everyday experience that there is a tremendous variety in the quality of the laughing sounds, so obviously deviations from the schwa occur. This does not contradict the hypothesis of an inarticulate vocalization per se but puts forward the task of defining the deviations from the resting articulation position that are due to altered emotional states and separate them from those supralaryngeal conditions modulating the sound that are due to voluntary actions.

A second factor that we need to take into account is that there are different ways to generate laughing sounds and it is possible to intentionally modulate the emotion-driven spontaneous laughter. As the cerebral organization of vocal behavior progressed phylogenetically after these early facio-vocal signals became hardwired, higher centers obtained control over the laughter "timer". Thus, in addition to laughing spontaneously (emotional laughter), we can laugh voluntarily or on command (contrived or faked laughter), and we can even speak or sing the laughing sounds, which typically are phonetically represented as "ha ha ha." These forms of utterances differ in degree of volitional control and -inversely-emotionality, and imply different neural pathways and systems involved (for reviews of neuronal control of vocalization see, for example, Jürgens, 1998; Ploog, 1986; for reviews or models of laughter: Arroyo et al., 1993; Fried et al., 1998). The distinction made between spontaneous and voluntary laughter is consistent with clinical observations; certain patients with degenerative brain disorders may be unable to move their abdomen voluntarily, but demonstrate vigorous expiratory movement of the abdomen when laughing spontaneously (Bright et al., 1986). Finally, it should be noted that there are also voluntary attempts to regulate spontaneous laughter; for sake of brevity the combination of voluntary and spontaneous in regulated laughter is only mentioned here. 
In spontaneous laughter we are following an impulse, an urge to laugh without restraining ourselves. There is no attempt to suppress the response or exert any control over its expression; the laughing person has been described as abandoning himself or herself to the body response (Plessner, 1941). The involuntary aspect can also be seen in the fact that during laughter our self-awareness and self-attention is diminished. Trying to direct attention during a laughter episode stops or reduces laughter. During laughter the state of consciousness is altered; as Hall and Allin (1897; p. 8-9) put it: "[t]he objective world has vanished and is forgotten, the proprieties and even the presence of others are lost, and the soul is all eye and ear to the one laughable object. Care, trouble, and even physical pain are forgotten, and the mind, as it were, falls back through unnumbered millennia and catches a glimpse of that primeval paradise where joy was intense and supreme." While descriptions of emotional experience are rather sparse and reports of subjects mainly refer to the awareness of the impulse to laugh, spontaneous laughter is clearly enjoyable.

In voluntary laughter we may want to produce a sound pattern like that of natural laughter. A typical everyday situation demanding faked laughter is when we want to signal somebody that we enjoyed a humorous message and join the laughter of others but actually do not feel any enjoyment. While voluntary laughter may pass over into involuntary laughter, we can not voluntarily produce emotional laughter. Interestingly, research has shown that contrived and spontaneous laughter within a person are strikingly similar with respect to the respirational pattern (suggesting a "laughter signature"); however, it is doubtful whether this is also the case for supralaryngeal systems. The many ways in which they differ still need to be described; this will be especially important when studying individual differences as laughter gets socialized during ontogenetic development. Research has made use of the fact that we can voluntarily alter key features, and thus studies of laughter at different vowels, pitch, and voice quality exist (Citardi et al., 1996; Habermann, 1955). Laughing on command is embarrassing to some, and thus the results obtained for contrived laughter are of limited value for describing spontaneous laughter as it may merge voluntary movements with unintended affective states.

Speaking or singing "ha ha" allows modulating the sound in many ways (e.g., stretching the length of vowels, emphasizing particular syllables), just as with other spoken words. As with voluntary laughter we intend to produce a particular sound pattern and we have even more control over the outcome; the major difference being that phonation is not based on forced breathing but on well dosed air supply resulting in less tracheal resonance, breathiness, and aspiration. Spoken laugh sounds may be devoid of emotional intonation; thus there will be less variability in melody, and the utterance will be more clearly articulated and often match the phonemes of a language. Emotional laughter and speech are rather independent; in fact, laughter and speech may co-occur, thereby lengthening the duration of laugh-pulses (Nwokah et al., in press). It remains to be verified that damage of the higher speech centers has little impact on the expression of tickle-induced emotional laughter. 


\section{Description of Laughter}

Laughter is not a term used consistently, nor is it precisely defined in research articles and even encyclopedias. In everyday life a smiling face is often referred to as "laughter" although the vocal element is entirely missing. Research studies usually focus on one or two systems of laughter rather than the integration of all the components involved. For example, a study of the acoustics of laughter typically restricts the investigation to the phonatory system and may arrive at the conclusion that the duration of laughter is, say, below two seconds. Sound production is contingent on air flow and the deviation from resting breathing exceeds the rhythmic forced exhalations underlying laughter by far; therefore duration estimates of eight seconds are not uncommon in respiration studies (e.g., Habermann, 1955). In studies of primate laughter the face gets most attention and also studies of joy in humans typically focus on the face, or even on the emotion-specific actions neglecting the mouth opening altogether. The analysis of videotaped laughter suggests a mean duration of five seconds while the study of facial muscle contractions exceeds this value due to the offset period where facial changes are barely visible (Ruch, 1990).

\subsection{Laughter Segmentation}

Laughter bout. The term laughter bout is used here to refer to the whole behavioral-acoustic event, including the respiratory, vocal, and facial and skeletomuscular elements. Prototypically, a laughter bout may be subdivided into an onset (i.e., the pre-vocal facial part which in explosive laughter is very short and steep); an apex (i.e., the period where vocalization or forced exhalation occurs), which -in sustained laughter- might be interrupted by inhalations; and an offset (i.e., a post-vocalization part; usually a long-lasting smile fading out smoothly).

Laugh cycle and laugh-pulse. The laughter vocalization period is composed of laugh cycles, i.e., repetitive laugh-pulses (Moore \& von Leden, 1958) interspersed with pauses. There is laughter with only one or two pulses ("exclamation" laughter, "chuckle"; Nwokah et al., 1993), but studies typically report a mode of four pulses in a laugh cycle (Provine \& Yong, 1991; Rothgänger et al., 1998). The upper number of pulses in a laugh cycle is limited by the lung volume, and different studies give numbers between 9 and 12 (Boeke, 1899; Provine \& Yong, 1991); a laughter episode -two or more laughter bouts separated by inspirations- will have more.

Table 1 presents an attempt to integrate empirical findings from studies of different systems involved in laughter. Obviously the same phenomenon was studied and converging information about the rhythmic pattern of laugh-pulses can be extracted from studies of air flow and pressure, respirational and laryngeal muscles, acoustics, and the oscillations in the pressure a finger puts on a plate. During intense laughter, the laugh-pulse would be extractable from different parts of the body, as the massive respiration movements cause vibrations of the trunk and limbs to occur which may be detected by an acceleration sensor on the body surface. 
Table 1. The laugh-pulse as studied in respiration, acoustics, and body movement

\begin{tabular}{|c|c|c|c|c|c|}
\hline \multirow[t]{2}{*}{ Author(s) } & \multirow[t]{2}{*}{ variable studied } & \multirow{2}{*}{$\begin{array}{l}\text { number of } \\
\text { pulses }\end{array}$} & \multicolumn{3}{|c|}{ duration (in ms) } \\
\hline & & & IPI & pulse & IPP \\
\hline \multicolumn{6}{|l|}{ Respiration } \\
\hline Bloch, Lemeignan and Aguilera (1991) & rectus abdominis muscle (EMG) & $4.17 / \mathrm{s}$ & 240 & & \\
\hline Hoit, Plassman, Lansing and Hixon (1988) & rectus abdominis muscle (EMG) & $5-6 / s$ & & & \\
\hline \multicolumn{6}{|l|}{ Air pressure } \\
\hline \multirow[t]{2}{*}{ Agostoni, Sant'Ambrogio and Portillo Carrasco (1960) } & gastric air pressure (swallowed balloon) & $5-6$ cycles/s & & & \\
\hline & thoracic air pressure (swallowed balloon) & $5-6$ cycles/s & & & \\
\hline Schroetter (1925) & exhaled air in closed system & up to $5 / \mathrm{s}$ & & & \\
\hline \multicolumn{6}{|l|}{ Laryngeal activity } \\
\hline Moore and van Leden (1958) & vocal fold vibrations (ultra high speed camera) & & & $30-100$ & \\
\hline \multirow[t]{3}{*}{ Luschei, Ramig, Baker and Smith (1997) } & thyroarytenoid muscle (EMG) & $5 \mathrm{~Hz}$ & & & \\
\hline & cricothyroid muscle (EMG) & $5 \mathrm{~Hz}$ & & & \\
\hline & posterior cricoarytenoid muscle (EMG) & $5 \mathrm{~Hz}$ & & & \\
\hline \multicolumn{6}{|l|}{ Acoustics } \\
\hline Boeke (1899) & "ha"-sounds/utterances & $4.12 / \mathrm{s}$ & 243 & 60 & 183 \\
\hline \multirow[t]{2}{*}{ Bickley and Hunnicutt (1992) } & laughter syllables & & 204 & 97 & 167 \\
\hline & laughter syllables & & 224 & 68 & 156 \\
\hline Nwokah, Davies, Islam, Hsu and Fogel (1993) & laugh events & & 200 & & \\
\hline \multirow{2}{*}{ Nwokah, Hsu, Davies and Fogel (1998) } & events & & & 110 & \\
\hline & events & & & 130 & \\
\hline Mowrer, LaPointe and Case (1987) & laugh bursts & $5.55 / \mathrm{s}$ & 180 & & \\
\hline Provine and Yong (1991) & laughter notes & $4.76 / \mathrm{s}$ & 210 & 75 & 135 \\
\hline Rothgänger, Hauser, Cappellini and Guidotti (1998) & plosives & $4.67 / \mathrm{s}$ & 213 & 126 & 87 \\
\hline \multicolumn{6}{|l|}{ Body vibrations (sentics) } \\
\hline Clynes (1980) & transient finger pressure (sentograph) & $5.03 / \mathrm{s}$ & 199 & & \\
\hline
\end{tabular}

Notes. Authors typically gave either frequency per second or the duration of utterances, or other information which was then transformed into one or both parameters by the author of the present chapter.

IPI = interpulse interval; IPP = interpulse pause 
While so far there is no convincing evidence for Darwin's (1872) claim that the muscles of the limbs are thrown into rapid vibratory movements at the same time as the respiratory muscles, initial support can be found in a sample figure provided by Santibañez and Bloch (1986). In this illustration of the EMG-recordings from the brachioradialis (forearm muscle which bends the elbow) and rectus femoris (anterior muscle of the upper thigh) muscles, an increase in amplitude can be found, and the rhythmic pattern seems to match the one of the abdominal muscles.

There are roughly five pulses per second, but the interpulse interval varies as a function of the position of the pulse in a sequence (Boeke, 1899; Provine \& Yong, 1991; Rothgänger et al., 1998). Further segmentation of the laugh-pulse can be obtained in the different systems involved in laughter. Boeke, recording his own laughter on an Edison Sonograph, already discovered the existence of pauses between the laughter sound pulses whose length exceeded the duration of the ha-utterances by a factor of two. Due to the dynamics of respiration, the duration of sound pulses decreases sequentially from an earlier to later position, and the duration of the interpulse pause increases. Differences in operational definitions of pulse and interpulse pause add further variations to the estimations of length (see Table 1).

Acoustic segmentation of the laugh-pulse. Acoustic analyses of laughter suggest a distinction between the vowel-like utterance nucleus and the preceding aspirated " $\mathrm{h}$ "-type sound initiating the sound pulse. As the glottis is open during the interpulse pauses, aspiration continues. Thus, not surprisingly, Provine and Yong (1991) report that laughter played backwards still sounds like "ha ha".

Vibratory movements in a laugh-pulse. At the level of laryngeal movements a laugh-pulse can be further split up into the number and duration of vibratory cycles of the vocal cords, and even further into their contour; i.e., the phases of when vocal cords are opening, closing, or closed. Using ultra high speed motion picture photography (4000 exposures a second), Moore and van Leden (1958) found in their analysis of the vibration of the cords during a man's laughter a range of 5 to $15 \mathrm{cy}$ cles of opening and closing in laugh-pulses. Accordingly, the duration of laughpulses varied from 30 to $100 \mathrm{~ms}$. Each vibratory cycle interrupts the air column ascending from the lungs and the rate of these cycles is the basis for the fundamental frequency of the sound. Further segmentation may be achieved by analyzing the time when vocal cords are opening, closing, or closed, and this vibratory curve contour reflects the dynamics of respiration as it undergoes a progressive change even within one laugh-pulse. These modifications in the vibratory pattern codetermine how laughter sounds and may be a key factor in distinguishing types of laughter.

\subsection{Laughter Respiration}

A respiration cycle consists of inspiration, inspiration pause, expiration, and expiration pause. No matter where in a respiration cycle a person is, laughter typically begins with an initial forced exhalation, followed by a more or less sustained sequence of repeated expirations of high frequency and low amplitude, which may 
or may not be phonated as "ha ha ha;" i.e., the laugh cycles. While in the case of sustained laughter the expiratory phases will be interrupted by inhalations, there is no evidence for Darwin's (1872; p. 199) assertion that "... [t] he sound of laughter is produced by a deep inspiration followed by short, interrupted, spasmodic contraction of the chest, and especially of the diaphragm." No inspiration preceding the laugh is necessary as laughter is produced at a low lung volume (Bright et al., 1986). Normally the laugh cycles are initiated around functional residual capacity (FRC; i.e., at the lung volume after a normal expiration) and terminate close to residual volume (i.e., the air volume remaining in the lung after maximal expiration), or sometimes even exceed the level of maximal voluntary exhalation (Bright et al., 1986; Lloyd, 1938). Thus, most likely the initial forced exhalation is expelling the tidal volume, and the following sequence of laugh-pulses is based on the expiratory reserve volume. The increase in depth of respiration -the amplitude during laughter may be up to 2.5 times higher than during resting respiration- is therefore due to the stronger expiration; inspiration may add to the amplitude in case of laugher episodes, where single deep inhalations intersperse the expiratory sequences.

The rhythmic laughter respiration pattern is produced by saccadic contractions of auxiliary expiration muscles; i.e., muscles that are typically passive during normal expiration, such as the diaphragm (Agostoni et al., 1960), the abdominal (rectus abdominis; Hoit et al., 1988; Santibañez \& Bloch, 1986) and the rib cage muscles (triangularis sterni; De Troyer et al., 1987). Of the three muscles mentioned, only the diaphragm is involved in resting breathing in humans; its contraction causes inspiration. The role of the diaphragm is not entirely clear, however, as the discharges in the EMG recordings (albeit parallel to the air pressure) may be indicating reflex contractions due to the passive distention occurring as a function of the violent contractions of the ribcage and abdominal muscles. The triangularis sterni is passive during quiet breathing but involved in different active respiration maneuvers; i.e., respiration below FRC. It contributes to the deflation of the rib cage during active expiration such as in coughing and its neural activation is largely coupled with that of the abdominals. The relative contribution of rib cage and abdomen to the volume may vary even within one laughter cycle (Bright et al., 1986; Habermann, 1955).

The respiratory muscles function in concert with the larynx; while without any closing of the glottis there may be single or a few forced exhalations, the adduction (closing) prevents the air to be exhaled too quickly, and allows the building up and maintaining of subglottal air pressure. The initial forced exhalation increases the transdiaphragmatic air pressure by about $5440 \mathrm{~Pa}$ (Agostoni et al., 1960) to about $6120 \mathrm{~Pa}$ (Schroetter, 1925); this pressure plateau is maintained and forms the basis for the sustained period of phonation of the laugh utterances. The heightened pressure makes the air stream up the airways through the larynx where the rhythmic closing and opening of the glottis interrupts the air stream. These vibrations are carried through the vocal tract whose shape amplifies or dampens certain frequency spectra, and finally the air escapes through the mouth or the nose. 


\subsection{Phonation}

The acoustic sequence of laughter pulses are produced by a series of rapid, continuous, stereotypic laryngeal adjustments, which are separated into four stages: interpulse pause, adduction (closing) of the arytenoid cartilages, vibration of vocal chords, and abduction (opening) of the arytenoid cartilages (Moore \& von Leden, 1958). As confirmed by laryngeal EMG during laughter the thyroarytenoid and -to a lesser extent- the cricothyroid muscles are involved in the closing of the glottis and the opening is achieved by the posterior cricoarytenoid muscle (Luschei et al., 1997). Both groups contract in the same pace (see Table 1), but with a time lag.

The interpulse pause is an instant of quiet between the audible moments of laughter. The arytenoid cartilages rest open allowing the breath stream to flow unimpeded through the larynx, and the vocal cords remain motionless. Some of the aspirate sound is produced at this time but becomes more audible as the vocal cords approach each other. The fact that the " $h$ " sound is an eddy-current phenomenon created during the closing stage of the valve-like movements of the vocal folds is in line with the assumption of the absence of cortically controlled articulation. Occasionally it was argued that glottal stops occur between the laugh-pulses; however, both videoendoscopy and photoglottography show that the glottis is widely open at the end of a laugh-pulse (Citardi et al., 1996; Moore \& van Leden, 1958) and the acoustic analyses reported quiet aspirations in the periods between voicing (e.g. Luschei et al., 1997).

During the adduction stage the arytenoid cartilages carry the cords toward each other and when the glottal space has been narrowed to a small slit, the cords begin to vibrate. As vibration occurs not only when the arytenoids are fully approximated but start at the end of the adduction and continue when abduction starts again there are transitions between an initial swing of the flaccid cords and the full vibrations and again towards the end of the vibratory movements. Moore and von Leden (1958) report that it takes about $10 \mathrm{~ms}$ to accomplish the transition from quiescence to full vibration, and that changes in vibratory curve contours and in the length of cycles occur as the laugh-pulse progresses. During the adduction phase of the laugh-pulse the arytenoids and vocal cords move into their rest positions. There is a progressive diminution of the mesial excursion of the cords and the slowing of the cord movement as the interarytenoid space enlarges; for example, in the sample laugh-pulse provided by Moore and von Leden (1958) there is a progressive drop of about 30 cycles per second.

Thus, whereas during singing we try to keep the fundamental frequency constant for each note, due to the dynamics of air flow there is tremendous variation even within a single laugh-pulse. Acoustic analyses also demonstrate the changes in fundamental frequency between laugh-pulses; typically there is a progressive decrease in pitch and intensity (loudness) of laughter at later pulses of a cycle. Boeke noted already in 1899 that the melodic variation in laughter is higher than in speech. 


\subsection{Supralyrangeal Modulation}

The buzzing sound produced in the glottis is carried into the resonance tract whose form codetermines the sound of laughter. While the laryngeal and respiratory movements during laughter appear to be highly stereotyped, the acoustic output is quite variable. There is little systematic research on the activity of the 10 or so movable articulators and thus at present a comprehensive evaluation whether the activity is compatible with the hypothesis of an inarticulate sound is not possible.

While one could predict that in courteous laughter without much emotional involvement the vowel uttered is schwa-like, in emotional laughter some supralaryngeal conditions modulating the sound occur, partly molded by the emotional state. Despite the assumption that there is no cortically controlled articulation in laughter, qualitative differences might be related to emotional states in various ways. Variations in pitch can be obtained by increasing or reducing the length of the vocal tract, for example, by lifting or lowering the larynx, or by protruding or retracting the lips. Indeed, both Habermann (1955) and Citardi et al. (1996) observed movement of the larynx in the superior-inferior direction during voluntary laughter. A further determinant of pitch, the lengthening and tension of the vocal cords, is susceptible to emotional arousal (contraction of the vocalis muscles) as is the general degree of tension vs. relaxation in the laryngeal area. Width or narrowness of the pharynx affects the voice quality, and it has been argued that in positive states there is a widening of the throat (as in taking up food) producing a-type sounds while in disgust there is a narrowing of the throat (as in expelling bad food) compatible with the sound during contemptuous or scornful laughter.

Of the major articulators in speech, the tongue (involved in producing high and low, and front and back vowels) is likely to be in a resting central position during joyful laughter, but the jaw and lips are not. The act of opening the mouth and the degree of aperture of the mouth (i.e., lowering of the jaw) affects the sound; this action is coupled with respiration (allows the escape of air). Habermann (1955) reported nasals occurring; this seems to be likely only for mild laughter, when the mouth is not opened, the soft palate lowered, and the air escapes through the nose. Last but not least, two important articulators, the lips and the cheeks, are typically not in a resting position as they are part of the emotion-driven facial actions. For example, the facial display of enjoyment involves the retraction of the lip corners and the cheeks are lifted upwards (see description of the specific muscles in section 2.5 below); the contraction of these two pairs of muscles changes the form of the mouth aperture and tenses the skin of the upper ending of the vocal tract thereby affecting the sound at the onset and apex of these actions. As Tartter (1980) demonstrated, the same spoken message sounds different when the sender is smiling or showing a resting face; listeners can reliably infer smiling from the voice. Intense smiling is also incompatible with the utterance of vowels which require a protruding of the lips, such as an "o" or "u," making these sounds unlikely to occur 
during joyful laughter. Taken together, these considerations would predict that laughter vowels would deviate from being a neutral vowel and the reason for a contrary finding is due to other constraints during emotional laughter.

Chimpanzee laughter. As the laryngeal apparatus and vocal tract of humans and primates are different in many ways (see Lieberman, 1975) one should not expect the similarities between primate and human laughter to be very strong. Chimpanzee laughter has been described as a soft repetitive guttural sound of low intensity panting noises during exhalation that roughly sounds like human laughter. The sound is based on rhythmic breathing resulting in staccato vocalizations. Spectro graphic analyses are sparse; Berntson et al. (1989) report that while generally "noisy," the laughter recordings from a juvenile male during active play evidenced temporal structure, with periodic louder voiced and voiceless components. They provide a sample figure with four distinct syllable-like louder egressive voiced segments. These segments were characterized by some low fundamental frequency voicing, with intermittent noise. Provine (1996) concludes that the major difference is that in human laughter several laugh-pulses may occur on one expiration, whereas chimpanzee laughter is produced during each brief expiration and inspiration. He notes that "... [t] he sounds of chimpanzee and human laughter are sufficiently different that without viewing the characteristic "play face" and source of stimulation (such as play and tickle), naive human beings may be unable to identify the chimpanzee vocalization as laughter" (Provine, 1996; p. 40).

\subsection{Facial Actions}

If the theory applies that sounds were initially added to the facial display to supplement or underscore a message then the emotion-specific facial configuration molded and also limited the sound utterance. Thus, the identification of the facial actions in spontaneous laughter is important. As laughter is commonly associated with the emotion of joy, the facial configuration named (Ekman et al., 1990) the Duchenne display (to honor Duchenne who first described how this pattern distinguished enjoyment smiles from other kinds of smiling) might serve as a first starting point against which, for descriptive purposes, deviations may be judged. The Duchenne display refers to the joint contraction of the zygomatic major and orbicularis oculi muscles (pulling the lip corners backwards and upwards and raising the cheeks causing eye wrinkles, respectively). While laughter has been described as occurring during different emotional states, so far it is not clear whether or not these laughs are also morphologically different. Furthermore, those voluntary facial actions aimed at modulating the intensity, duration or quality of the sound emitted, or to suppressing laughter altogether are not completely identified. Another starting point may be the facial display during primate laughter. This is circular, in part, as the human facial actions have been the basis for homologizing the primate displays.

Primate laughter. The facial features of primates have been described by salient features, rather than their muscular underpinning. The play face (or relaxed open- 
mouth display) in chimpanzees has been described as the jaws being widely open, the mouth corners normal or slightly retracted, the upper lip covering the teeth, lower lips loose, and the lower teeth exposed. This description seems to involve the action of the zygomatic major, but not the orbicularis oculi muscles, although it is developed in chimpanzees. However, most of this work (e.g., Chevalier-Skolnikoff, 1973; van Hooff, 1972) was done before the rediscovery of Duchenne, and therefore the actions of this muscle were perhaps not specifically studied.

Human laughter. The facial expression of laughter has been given some attention by researchers during the past and present century. A summary of hypotheses put forward and the results of some studies of laughter using facial-EMG (surface and needle electrodes) or the Facial Action Coding System (Ekman \& Friesen, 1978) are presented in Table 2. It should be noted, however, that early descriptions had to be based on real time observations, or on inferences from knowledge about facial musculature since no recording tools were available. As intense laughter involves movement of head and trunk, facial measurement continues to be a problem.

Table 2 confirms that the two muscles forming the Duchenne smile have been found to be involved in laughter as well, explaining the smooth transitions between smiling and laughter in both the onset and offset of a laughter bout. Sumitsuji (pers. comm.) observed that there is little innervation of the orbicularis oculi muscle during voluntary laughter; thus the eye region might serve as a marker for distinguishing emotional from voluntary laughter, much as it does for distinguishing enjoyment from non enjoyment smiling. Interestingly, in two forms of pathological laughter (epileptic laughter and pseudo bulbar palsy; representing excitation or the loss of inhibition, respectively), the activated motor pattern includes the contraction of the orbicularis oculi muscle. Furthermore, laughter includes the relaxation of some muscles (masseter, pterygoids) allowing for a lowering of the lower jaw so that the air is expelled through the mouth.

However, the number of postulated and confirmed muscles involved in the laughter facial expression are far more than those usually identified. So how do we make sense of the true complexity of the neuromuscular patterns of laughter given the limited and contradictory information currently available? First, several of the additional muscles may be involved in auxiliary movements, perhaps of secondary importance; this might be the case for the muscles located around the mouth, such as the levator labii superioris, depressor anguli oris, risorius, or orbicularis oris. They are involved in the radial opening of the lips aimed at widening the mouth to let the air stream out more easily. Second, some of the hypotheses relate to the intensity of laughter. It has been suggested that strong laughter also involves the muscles in the upper face, such as the corrugator supercilii and the frontalis muscles. Moreover, claims have been made that with increasing intensity of laughter almost all muscles get involved and tensed (Heller, 1902) and that the most intense form of laughter is not well distinguishable from the facial display of crying (Darwin, 1872; Piderit, 1867). There is no support for this from the existing studies of healthy 
Table 2. Hypotheses and empirical findings regarding the involvement of facial muscles in laughter

\begin{tabular}{|c|c|c|c|c|c|c|c|c|c|c|c|c|c|c|c|c|c|c|}
\hline \multirow[b]{2}{*}{ Author(s) } & \multicolumn{6}{|c|}{ upper face muscles } & \multicolumn{6}{|c|}{ mid-face muscles } & \multicolumn{6}{|c|}{ lower face muscles } \\
\hline & 1 & 2 & 3 & 4 & 5 & 6 & 7 & 8 & 9 & 10 & 11 & 12 & 13 & 14 & 15 & 16 & 17 & 18 \\
\hline \multicolumn{19}{|l|}{ Hypotheses: laughter } \\
\hline Bloch et al. (1987) & & & & & $X$ & $\mathrm{X}$ & $\mathrm{X}$ & & & & & & & & & & & $X$ \\
\hline Darwin (1872) & & & & & $X$ & $\mathrm{X}$ & $\mathrm{X}$ & & $\mathrm{X}$ & $X ?$ & & & & & & & & \\
\hline Dearborn (1897) & & & $\mathrm{X}$ & $X$ & & $\mathrm{X}$ & $\mathrm{X}$ & $\mathrm{X}$ & $\mathrm{X}$ & $X$ & $\mathrm{X}$ & & $\mathrm{X}$ & & & $X$ & & \\
\hline Hecker (1873) & & & & & & & $\mathrm{X}$ & & $\mathrm{X}$ & $\mathrm{X}$ & & & & & & & & \\
\hline Heller (1902) & & & & & $X$ & $\mathrm{X}$ & $\mathrm{X}$ & & & & & & $\mathrm{X}$ & & & & & \\
\hline Hjortsjö (1970) & $\mathrm{X}$ & $\mathrm{X}$ & & & $\mathrm{X}$ & $\mathrm{X}$ & $\mathrm{X}$ & $X$ & & $\mathrm{X}$ & & $X$ & $\mathrm{X}$ & & & & & $\mathrm{X}$ \\
\hline Piderit (1867) & & & & & & & $X$ & $X$ & $\mathrm{X}$ & & & & $X$ & & $X$ & & & \\
\hline Poeck and Pilleri (1963) & & & & & $\mathrm{X}$ & & $\mathrm{X}$ & & & & $X$ & & & $\mathrm{X}$ & & & & \\
\hline Raulin (1900) & & & & & $\mathrm{X}$ ? & & $X$ & $X$ & & & & & $\mathrm{X}$ & & & & & \\
\hline \multicolumn{19}{|l|}{ Hypotheses: strong laughter } \\
\hline Darwin (1872) & & & $\mathrm{X}$ & & $\mathrm{X}$ & $\mathrm{X}$ & $\mathrm{X}$ & & $\mathrm{X}$ & $X ?$ & & & & & & & & \\
\hline Heller (1902) & $X$ & $\mathrm{X}$ & $\mathrm{X}$ & $X$ & $X$ & $X$ & $X$ & & & $\mathrm{X}$ & & & $\mathrm{X}$ & & & & $\mathrm{X}$ & \\
\hline Piderit (1867) & & & $\mathrm{X}$ & & & & $X$ & $X$ & $\mathrm{X}$ & & & & $\mathrm{X}$ & & $X$ & & & \\
\hline \multicolumn{19}{|l|}{ Results: FACS-studies } \\
\hline Grammer (1990) & & & & & & & $\mathrm{X}$ & & & & & & & & & & & \\
\hline Keltner and Bonanno (1997 & & & & & $X$ & & $\mathrm{X}$ & & & & & & & & & & - & \\
\hline Ruch $(1990,1994)$ & & & & & $\mathrm{X}$ & $\mathrm{X}$ & $\mathrm{X}$ & & & & & & & & & & - & \\
\hline Ruch (1997) & & & & & $X$ & & $X$ & & & & & & & & & & - & \\
\hline \multicolumn{19}{|l|}{ Results: EMG-studies } \\
\hline Gallo and Palla (1995) & & & & & & & & & & & & & & & & & $\mathrm{X}$ & \\
\hline Santibañez et al. (1986) & & & & & & & & & & & & & & $X$ & & & $\mathrm{X}$ & \\
\hline Sumitsuji (1967) & - & - & - & & $\mathrm{X}$ & & $X$ & & $\mathrm{X}$ & & & & $\mathrm{X}$ & $\mathrm{X}$ & $X$ & $X$ & & \\
\hline Tanaka (1976) & - & - & - & & $\mathrm{X}$ & & $\mathrm{X}$ & & & & & & & & & $X$ & & \\
\hline Tanaka et al. (1991) & - & - & - & & $X$ & & $X$ & & $\mathrm{X}$ & & & & $\mathrm{X}$ & & & $X$ & & \\
\hline \multicolumn{19}{|l|}{ Supressed laughter } \\
\hline Tanaka (1976) & $\mathrm{X}$ & $\mathrm{X}$ & & & $X$ & & $\mathrm{X}$ & & & & & & & & & & & \\
\hline \multicolumn{19}{|l|}{ Pathological laughter } \\
\hline Tanaka et al. (1991) & $X$ & $\mathrm{X}$ & $X$ & & $X$ & & $X$ & & $\mathrm{X}$ & & & & $\mathrm{X}$ & & & $X$ & & \\
\hline Yamada et al. (1994) & & & $\mathrm{X}$ & & & & & & & & & & & & & & & \\
\hline
\end{tabular}

Notes. $1=$ frontalis, pars medialis-raises the inner brows, producing horizontal furrows in the medial region of the forehead; 2 =frontalis, pars lateralis-raises the outer brows, producing horizontal furrows in the lateral regions of the forehead; 3 =corrugator supercilii-draws the brows together and downward, producing vertical furrows between the brows; 4=pyramidalis/procerus/depressor supercilii-pulls the medial part of the brows downward and may wrinkle the skin over the bridge of the nose; $5=$ orbicularis oculi, pars orbitalis-tightens the skin surrounding the eye causing crows-feet wrinkles; $6=$ orbicularis oculi, pars palpebralis-tightens the skin surrounding the eye causing the lower eyelid to raise; 7=zygomaticus major-pulls the lip comers up and back; 8=zygomaticus minor-deepens nasolabial furrow; 9=levator labii superioris/levator labii superioris, caput infraorbitalis-raises the upper lip and flares the nostrils, exposing the canine teeth; 10=levator labii superioris alaeque nasi-raises the center of the upper lip and flares the nostrils; 11=nasalis, pars alaris bzw. dilatores nasi-dilates nostrils; 12=buccinator-compresses and tightens the cheek, forming a dimple; 13=risorius-stretches lip corners straight to the side; 14=orbicularis oris-tightens, compresses, protrudes, or inverts the lips; 15=depressor anguli oris-pulls the lip comers downward; $16=$ mentalis-raises the chin and protrudes the lower lip; 17=masseter-adducts the lower jaw; $18=$ caninus/levator anguli oris-pulls the lip corner up sharply and puffs up cheeks.

A "X" includes action of that muscle, a "-" means lowering of muscle tone. Authors either gave names or picture of muscles or a description of facial appearance from which the muscle action was then inferred utilizing the information provided by the Facial Action Coding System (Ekman \& Friesen, 1978). An "?" was added when the muscle is not entirely clear from the description given. 
adults; on the contrary, Tanaka and Sumitsuji (1991) report a lowering of muscle tone in the upper face during laughter (as has been found for the corrugator supercilii in smiling). However, in pathological laughter -usually of high intensity- the frontalis and corrugator muscles are active (Tanaka \& Sumitsuji, 1991). This would seem to support an intensity hypothesis; however, as patients do not enjoy laughter fits, the additional movements might be of voluntary nature reflecting efforts to control or suppress laughter rather than being part of an innate response pattern.

Third, some muscles may be active only part of the time and the course of contraction of muscles over time can be different for different muscles. For example, the masseter (chewing muscle) whose relaxation initially helps to lower the jaw, was found to have elevated activity during laughter (Gallo \& Palla, 1995; Santibañez \& Bloch, 1986). Unfortunately, studies often report only intensity of a muscle contraction without considering its distribution over time. Fourth, one has to take into account that researchers might have erred in transforming their observations into the list of muscles due to the lack of profound knowledge of the effects of muscle contraction on the appearance on the surface at that time. This might have resulted in identifying the wrong muscle (e.g., the early anatomists' labeling of the "risorius" seems to imply that they considered it to be the major laughing muscle), or too many muscles (e.g., the strong action of the zygomatic major is able to cause changes -like opening the nostrils or raising the upper lips- that can also be attributed to separate muscles). Fifth, in previous studies, the type of laughter often was not controlled for and this might account for some of the additional muscle actions observed. Instead of pure enjoyment there might have been voluntary laughter, a blend of enjoyment with other emotions (e.g., surprise should add the elevation of the eyebrows caused by the frontalis muscles), movements associated with regulating the intensity of laughter, attempts to suppress laughter, or even accidental movements. Of course, a significant yet unexplored remaining cause for these surplus facial actions might be that laughter during different emotional states (e.g., scorn, nervousness, embarrassment) is morphologically different.

The information in Table 2 is not yet complete, as not all facial muscles have been studied so far. It seems advisable to supplement future facial EMG-studies by videotapes of face and body to control for the nature of movement. Furthermore, it seems essential to vary and control for the quality of laughter, guarantee for different intensity levels, and also examine the course of muscle contractions over time rather than studying sheer intensity at apex. We also need to start separating voluntary and spontaneous actions based on the existing experience (Ekman, 1997).

Further facial changes. Several authors described a brightening of the eyes (even among chimpanzees); the sparkling quality was explained either by enhanced lacrimation or an enhanced tenseness owing to the contraction of the muscles around the eye (Darwin, 1872), or that the eyeballs get filled with blood or other fluids (due to the enhanced circulation; Piderit, 1867). Furthermore, there is the observation that a laughter episode is frequently terminated by a closing of the lids. 


\subsection{Body Movement}

While smiling is purely facial, at higher intensity levels laughter involves the whole body; however, changes in posture and body movements have received least attention in the study of laughter. Darwin writes (1872; p. 206-207) "During excessive laughter the whole body is often thrown backward and shakes, or is almost convulsed." Indeed, one can expect actions associated with the respiratory movements; for example, the backward tilt of the head facilitates the forced exhalations, and the forced inhalation interrupting two laughter cycles will raise and straighten the trunk. Furthermore, as noted above, the massive respiratory movements underlying the laughter pulse may cause the observed shaking of the shoulders and vibrations detectable on the trunk but also extremities.

There are also actions not coupled with respiration but their exact list and the conditions of their emergence are not known. As laboratory studies rarely induce violent laughter one has to rely on observations and self-reports such as the one by Hall and Allin who issued an 11 item questionnaire on tickling, fun, wit, humor, and laughing as a supplement to The American Journal of Psychology. In a subsequent report, they present a qualitative analyses based on responses of 3000 people (Hall \& Allin, 1897). Regarding body movements they summarize (p. 5) "... [i]n the height of the laugh ... some plant the elbows on the knees; others rock violently sideways, or more often back and forth; the hands are thrown into the air or clapped on the thighs; ... the limbs jerk; the foot is stamped; the fists pound; ... waves of nervous tremor pass over the body; ... the hand is placed over the eyes, mouth, or both; ... little children jump up and down, lie on the floor and roll all over the room; some swing the hands in the air; the breast heaves up and down; some turn around on the heel from left to right ... the head shakes from side to aide; ... others always hold the sides with both bands; others roll the head; features often twitch or tremble convulsively." Obviously, research is needed sorting accidental actions, attempts to regulate laughter and genuine elements of a laughter pattern.

\section{Concluding remarks}

The present review makes clear that the we need multi-level studies of laughter, as different systems work together in the generation of the expressive pattern and there are multiple dependencies among respiration, facial action, acoustics, and body movements. The review was restricted to some basic elements (leaving out issues such as neurohormonal effects of laughter, or social factors in laughter), since these provide the basis for tackling the yet unanswered questions of how to detect whether laughter is faked or felt, how to distinguish among different types of emotional laughter on a morphological basis, and what is the relationship between smiling and laughter. The list of unanswered questions and unsolved problems seems endless, but the study of laughter is a worthwhile subject as it is a window to ancient affective experience; a prototype of the prelingual utterance of joy. 


\section{Acknowledgments}

The preparation of this chapter was facilitated by a Heisenberg grant ( $\mathrm{Ru} 480 / 1-2)$ from the German Research Council (DFG) awarded to the first author. Thanks to Eva Nwokah and Rod Martin for comments on an earlier version of the chapter.

\section{References}

Agostoni, E., G. Sant'Ambrogio and H. del Portillo Carrasco (1960) "Elettromiografia del diaframma e pressione transdiaframmatica durante la tosso, lo sternuto ed il riso", Accademia Nazionale dei Lincei, Roma 28:493-496.

Arroyo, S., R. Lesser, B. Gordon, S. Uematsu, J. Hart, P. Schwerdt, K. Andreasson and R. Fisher (1993) "Mirth, laughter and gelastic seizures", Brain 116:757-780.

Berntson, G.G., S.T. Boysen, H.R. Bauer and M.S. Torello (1989) "Conspecific screams and laughter: Cardic and behavioral reactions of infant chimpanzees", Devel. Psychobiol. 22:771-787.

Bickley, C. and S. Hunnicutt (1992) "Acoustic analysis of laughter", Proc. Int. Conf. Spoken Language Process 2:927-930.

Bloch, S., M. Lemeignan and N. Aguilera (1991) "Specific respiratory patterns distinguish among human basic emotions", Int. J. Psychophysiol. 11:141-154.

Bloch, S., P. Orthous and G. Santibañez (1987) "Effector patterns of basic emotions: A psychophysiological method for training actors", J. Soc. Biol. Struct. 10:1-19.

Boeke, W. (1899) "Mikroskopische Phonogrammstudien", Pflüg. Arch. 76:497-516.

Bright, K.E., T.J. Hixon and J.D. Hoit (1986) "Respiration as a laughing matter", in: WHIMSY IV, D.L.F. Nilsen, ed., Tempe: Arizona State University, Department of English, pp. 147-148.

Chevalier-Skolnikoff, S. (1973) "Facial expression of emotion in nonhuman primates", in: Darwin and Facial Expression, P. Ekman, ed., New York: Academic Press, pp. 11-89.

Citardi, M.J., E. Yanagisawa and J. Estill (1996) "Videoendoscopic analysis of laryngeal function during laughter", Ann. Ot. Rhin. Lar. 105:545-549.

Clynes, M. (1980) "The communication of emotion: Theory of sentics", in: Emotion. Theory, Research, and Experience (Vol. 1, Theories of Emotion), R. Plutchik and H. Kellerman, eds., New York: Academic Press, pp. 271-301.

Darwin, Ch. (1872) The Expression of the Emotions in Man and Animals, London: Murray [3rd edition edited by Paul Ekman. Oxford University Press, New York, 1998].

Dearborn, G.V.N. (1897) "The emotion of joy", Psychol. Rev., Mon. Suppl., 2.

De Troyer, A., V. Ninane, J.J. Gilmartin, C. Lemerre and M. Estenne (1987) "Triangularis sterni muscle use in supine humans", J. Appl. Physiol. 62:919-925.

Ekman, P. (1997) "What have we learned by measuring facial behavior", in: What the Face Reveals, P. Ekman and E.L Rosenberg, eds., Oxford: Oxford University Press, pp. 469-485. 
Ekman, P., R.J. Davidson and W.V. Friesen (1990) "The Duchenne smile: Emotional expression and brain physiology II", J. Personal. Soc. Psychol. 58:342-353.

Ekman, P. and W.V. Friesen (1978) The Facial Action Coding System (FACS), Palo Alto, CA: Consulting Psychologists Press.

Fried, I., Ch.L. Wilson, K.A. MacDonald and E.J. Behnke (1998) "Electric current stimulates laughter", Nature 391:650.

Gallo, L.M. and S. Palla (1995) "Activity recognition in long-term electromyograms", J. Oral. Rehabil. 22:455-462.

Grammer, K. (1990) "Stangers meet: Laughter and nonverbal signs of interest in opposite-sex encounters", J. Nonverbal Behav. 14:209-236.

Habermann, G. (1955) Physiologie und Phonetik des lauthaften Lachens, Leipzig, Germany: Barth.

Hall, G.S. and A. Allin (1897) "The psychology of tickling, laughing, and the comic", Am. J. Psychol. 9:1-41.

Hecker, E. (1873) Die Physiologie und Psychologie des Lachens und des Komischen, Berlin, Germany: Dümmler.

Heller, H.V. (1902) Grundformen der Mimik des Antlitzes, Vienna, Austria: Schroll. Hjortsjö, C.H. (1970) Man's Face and Mimic Language, Lund: Studentlitteratur.

Hoit, J.D., B.L. Plassman, R.W. Lansing and T.J. Hixon (1988) "Abdominal muscle activity during speech production", J. Appl. Physiology 65:2656-2664.

Jürgens, U. (1998) "Neuronal control of mammalian vocalization, with special reference to the squirrel monkey", Nat. Wiss. 85:376-388.

Keltner, D. and G.A. Bonanno (1997) "A study of laughter and dissociation: Distinct correlates of laughter and smiling during bereavement", J. Personal. Soc. Psychol. 45:1313-1324.

Lloyd, E.L. (1938) "The respiratory mechanism in laughter", J. Gen. Psychol. 19: 79-189.

Lieberman, P. (1975) On the Origins of Language, New York: Macmillan.

Luschei, E.S., L. Ramig, K. Baker and M. Smith (1997) Coordination of the laryngeal and respiratory systems during spontaneous laughter, Unpublished Manuscript, Department of Speech Pathology, University of Iowa, Iowa City, USA.

Moore, P. and H. von Leden (1958) "Dynamic variations of the vibratory pattern in the normal larynx", Fol. Phoniat. 10:205-238.

Mowrer, D.E., L.L. LaPointe and J. Case (1987) "Analysis of five acoustic correlates of laughter", J. Nonverbal Behav. 11:191-199.

Niemitz, C. (1990) "Visuelle Zeichen, Sprache und Gehirn in der Evolution des Menschen-Eine Entgegnung auf McFarland", Z. Sem. 12:323-336.

Nwokah, E., P. Davies, A. Islam, H. Hsu and A. Fogel (1993) "Vocal affect in three-year-olds: a quantitative acoustic analysis of child laughter", J. Acoust. Soc. Amer. 94:3067-3090.

Nwokah, E., H. Hsu, P. Davies and A. Fogel (in press) "The integration of laughter and speech in vocal communication: A dynamic systems perspective", JSLHR. 
Piderit, T. (1867) Mimik und Physiognomie, Detmold, Germany: Meyer.

Plessner, H. (1941) Lachen und Weinen, Bern, Switzerland: Francke.

Ploog, D. (1986) "Biological foundations of the vocal expressions of emotion", in: Emotion: Theory, Research, and Experience (Vol. 3), R. Plutchik and H. Kellerman, eds., New York: Academic Press, pp. 173-197.

Poeck, K. and G. Pilleri (1963) "Pathologisches Lachen und Weinen", Schw. Arch. Neurol. Neurochirur. Psychiat, 92:323-370.

Preuschoft, S. (1995) "'Laughter' and 'smiling' in Macaques--An Evolutionary Perspective”, Utrecht: University of Utrecht.

Provine, R.R. (1996) "Laughter", Am. Sci. 84:38-45.

Provine, R.R. and Y.L. Yong (1991) "Laughter: A stereotyped human vocalization", Ethology 89:115-124.

Raulin, J.M. (1900) Le rire et les exhilarants, Paris, France: Baillière.

Rothgänger, H., G. Hauser, A. Cappellini and A. Guidotti (1998) "Analysis of laughter and speech sounds in Italian and German students", Nat. Wiss. 85:394-402.

Ruch, W. (1990) Die Emotion Erheiterung. Unpublished Habilitation thesis, University of Düsseldorf, Department of Psychology, Düsseldorf, Germany.

Ruch, W. (1993) "Exhilaration and humor", in: Handbook of Emotions, M. Lewis and J.M. Haviland, eds., New York, NY: Guilford Publications, pp. 605-616.

Ruch, W. (1994) "Extraversion, alcohol, and enjoyment", Pers. Individ. Diff. 16:89102.

Ruch, W. (1997) "State and trait cheerfulness and the induction of exhilaration: A FACS study", Europ. Psychol. 2:328-341.

Santibañez, G. and S. Bloch (1986) "A qualitative analysis of emotional effector patterns and their feedback", Pav. J. Biol. Sci. 21:108-116.

Schroetter, H. (1925) "Zur Kenntnis des Energieverbrauches bei emotiven Äußerungen des Seelenlebens", Monatsschr. Ohrenheilkd. Laryngo-Rhinol. 59:82-108.

Sumitsuji, N. (1967) "Electromyographic studies on the facial expression", Psych. Neurol. Jap. 69:1101-1119.

Tanaka, M. (1976) "Psychophysiological study on the emotional reaction induced by television and movies in schizophrenia", Med. J. Os. Univ. 28: 205-216.

Tanaka, M. and N. Sumitsuji (1991) "Electromyographic study of facial expressions during pathological laughing and crying", Electromyography and Clinical Neurophysiology 31:399-406.

Tartter, V.C. (1980) "Happy talk: Perceptual and acoustic effects of smiling on speech", Percept. Psychophys. 27:24-27.

Van Hooff, J.A.R.A.M. (1972) "A comparative approach to the phylogeny of laughter and smiling", in: Non-verbal Communication, R.A. Hinde, ed., Cambridge: Cambridge University Press, pp. 209-241.

Yamada, N., H. Tanabe, H. Kazui, M. Ikeda, M. Hashimoto, S. Sakamoto, J. Sawada and J. Shiraishi (1994) "A case of lobar athrophy with stereotypic unusual laughing", Brain and Nerve 46:781-786. 


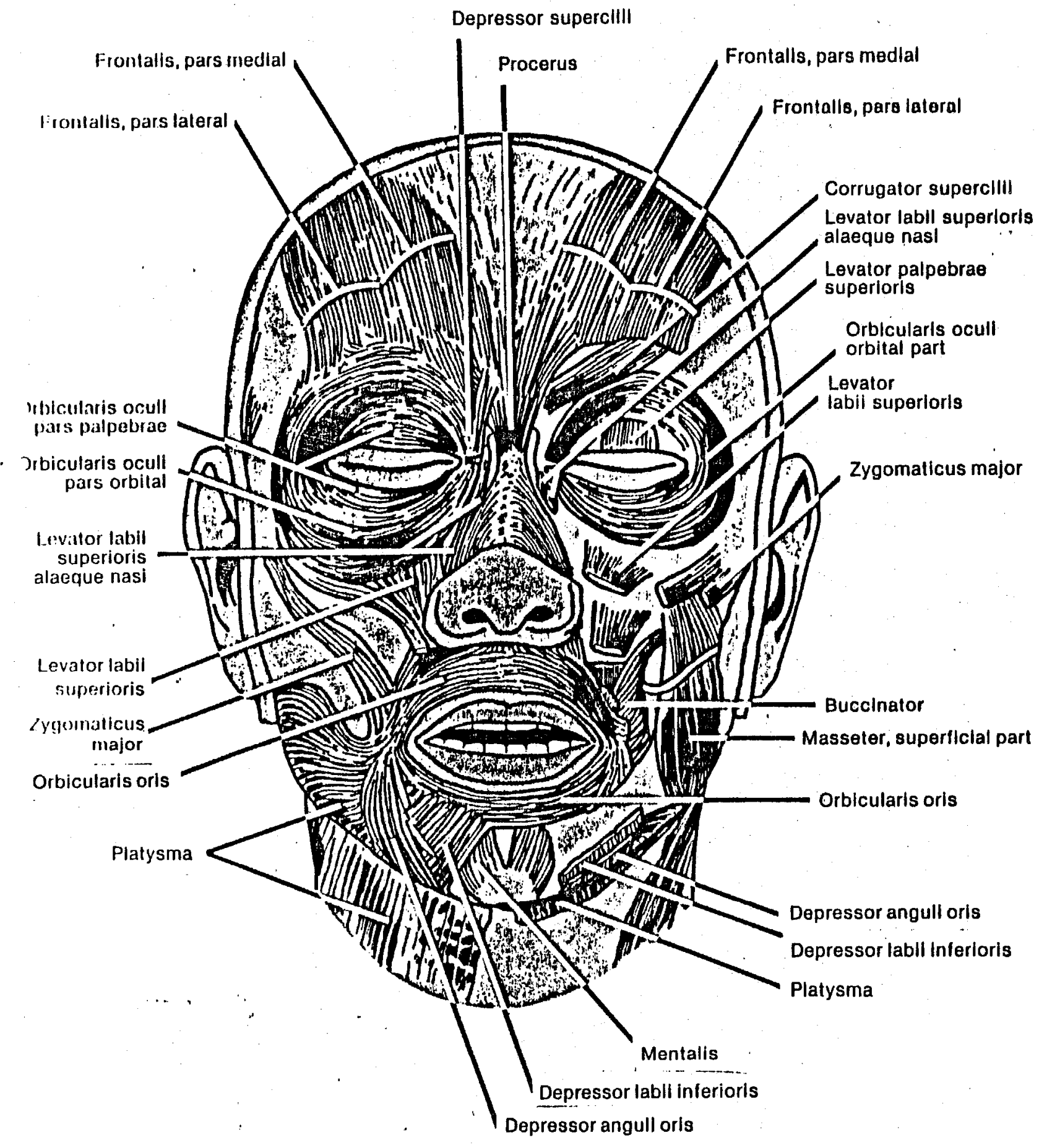

